American Journal of Applied Sciences 8 (6): 635-643, 2011

ISSN 1546-9239

(C) 2011 Science Publications

\title{
Simplified Procedure for Unsaturated Flow Parameters
}

\author{
${ }^{1}$ Natthawit Jitrapinate, ${ }^{2,3}$ Vichai Sriboonlue, \\ ${ }^{3}$ Kriengsak Srisuk and ${ }^{1}$ Dolrerdee Hormdee \\ ${ }^{1}$ Department of Civil Engineering, Faculty of Engineering, \\ Khon Kaen University, Muang District, Khon Kaen 40002, Thailand \\ ${ }^{2}$ Department of Agricultural Engineering, Faculty of Engineering, Thailand \\ ${ }^{3}$ Groundwater Research Center, Faculty of Technology, Thailand
}

\begin{abstract}
Problem statement: The unsaturated hydraulic conductivity $\mathrm{K}(\theta)$ and Soil Water Characteristic Curve (SWCC) for saline soil or soil directly contacted with saline water are not permitted using several apparatus to determining. Approach: A simplified method to determine $\mathrm{K}(\theta)$ and SWCC by using simple apparatus is presented. Using the proposed numerical model with the van Genuchten equations and inverse calculation for $K(\theta)$ and SWCC to produce the best fit of this model calculation to the experimental cumulative capillary flow in dry soil columns. These are found by an optimization procedure which adjusts the parameters of $\mathrm{K}(\theta)$ and SWCC. In addition, the resulting SWCC from the model was used to evaluate the $K(\theta)$ for the Gardner equation. Results: Values of saturated hydraulic conductivity $\mathrm{K}_{\text {sat }}$ for the van Genuchten equations were lower than those based on the Gardner equation. The $\mathrm{K}_{\text {sat }}$ values of dense soil were nearly overall lower than loose soil. Conclusion: Good agreement $\left(\mathrm{R}^{2}\right.$ value) was obtained in the SWCC and $\mathrm{K}_{\text {sat }}$ values from the experiment and those calculated from the van Genuchten and Gardner equations this suggests that the simplified method provides a useful means of determining unsaturated flow parameters.
\end{abstract}

Key words: Capillary flow, hydraulic conductivity, Soil Water Characteristic Curve (SWCC), soil compaction, saline soil, capillary fringe, hydraulic properties, volumetric moisture, tensiometer measurement, sandy loam

\section{INTRODUCTION}

Saline soils in the north-east of Thailand where is sub-humid areas cover an area of approximately 2.85 Mha. Salt-affected soils in this region are generally sandy, low in fertility and high in sodium and chloride content (Arunin, 1992). A major cause of salt reaching the surface in this area is due to the rise of saline watertables to the capillary fringe and consequently the rise of salt to the surface (Konyai et al., 2009; Löffler and Kubiniok, 1988). Upward movement of these saline waters contributes to the salinisation of the area.

The main objective of this study was to develop a simplified method for determining the unsaturated hydraulic conductivity $\mathrm{K}(\theta)$ and Soil Water Characteristic Curve (SWCC) for saline soils or soils directly in contact with saline water. Saline soil is not always permitted using several apparatus (e.g., tempe cell and hanging water column) for evaluation the soil hydraulic properties. The sample soils were kept after rainy season from 3 different locations (St1-St3) of saltaffected soil area for experiment in laboratory. In solution of the unsaturated hydraulic properties of saline soils, we imitated the occurrence of saline soil by capillary process of saline water. The capillary rise is induced in dry soil columns and the cumulative capillary flow is observed. In addition, the sample soil was compacted in soil columns with two different compactions for evaluation of the parameters of unsaturated hydraulic properties.

Using a numerical solution of the Richards Equation to determine these parameters in an assumed form of the $K(\theta)$ function. By inverse method measure flow under transient conditions and use a numerical model with the van Genuchten (1980) equations for $\mathrm{K}(\theta)$ and SWCC to determine the value of parameters that produced the best fit of the model predictions to the observed cumulative capillary flow in dry soil columns. The resulting SWCC is the primary wetting SWCC and be compared to experimental data from hanging water column method.

Corresponding Author: Natthawit Jitrapinate, Department of Civil Engineering, Faculty of Engineering, Khon Kaen University, Muang District, Khon Kaen 40002, Thailand 
In addition, we evaluated the unsaturated hydraulic conductivity $K(\theta)$ for the Gardner (1958) equation with the resulting SWCC of the van Genuchten (1980) equations. Using the resulting values to evaluate the capillary flow with the HYDRUS-1D software version 4.14 and compare to this proposed model.

Theoretical background: When we immerse the lower end of dry soil column in a pool of saline water, capillary rise is taking place. We modeled the unsaturated upward movement by Richards' equation as:

$$
\frac{\partial \theta}{\partial \mathrm{t}}=\frac{\partial}{\partial \mathrm{z}}\left(\mathrm{K}(\theta) \frac{\partial \psi}{\partial \mathrm{z}}+\mathrm{K}(\theta)\right)
$$

Where:

$\theta=$ Volumetric water content

$\psi=$ Pressure head

$\mathrm{T}=$ Time

$\mathrm{Z}=$ Vertical distance

$\mathrm{K}=$ Hydraulic conductivity which is not constant but is a function of $\theta$ which can be model by van Genuchten's formula as:

$\mathrm{K}(\theta)=\mathrm{K}_{\mathrm{sat}} \theta_{*^{\frac{1}{2}}}\left(1-\left(1-\theta_{*}^{\frac{1}{\mathrm{~m}}}\right)^{\mathrm{m}}\right)^{2}$

where $\theta_{*}$ is the effective saturation:

$$
\theta_{*}=\frac{\theta-\theta_{\mathrm{r}}}{\theta_{\mathrm{s}}-\theta_{\mathrm{r}}}
$$

with $\theta_{\mathrm{s}}$ and $\theta_{\mathrm{r}}$ being the saturation and residual volumetric moisture contents, respectively. The parameter $\mathrm{m}$ can be obtained from SWCC as:

$$
\theta=\theta_{\mathrm{r}}+\frac{\theta_{\mathrm{s}}-\theta_{\mathrm{r}}}{\left[1+(\alpha|\psi|)^{\mathrm{n}}\right]^{\mathrm{m}}}
$$

Where, $\alpha$ and $\mathrm{n}$ are parameters directly related to the shape of the $\theta(\psi)$ curve and a considerable simplification is gained by assuming that $\mathrm{m}=1-1 / \mathrm{n}$. The value of $\mathrm{K}_{\text {sat }}$ can be evaluated separately using various methods (e.g., falling head permeameter, constant head permeameter and by interpreting from physical properties). In this study, we evaluated values of $\mathrm{K}_{\mathrm{sat}}$ and the other parameters using the inverse method.

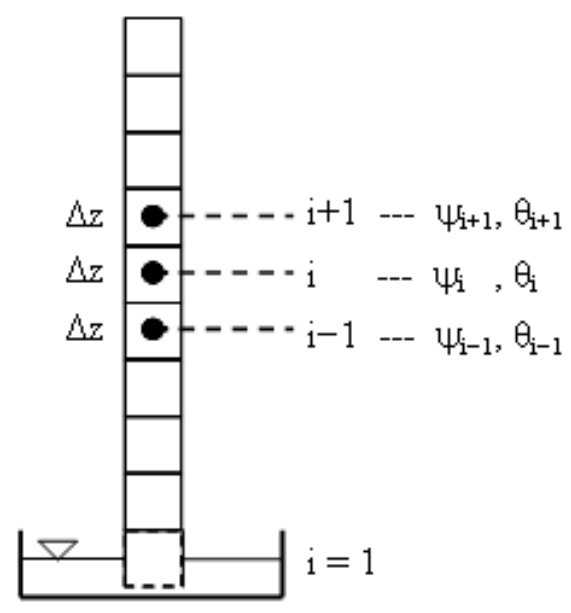

Fig. 1: A soil column immersed in a pool of saline water

The inverse method involved preparation of dry, compaction, soil columns to be tested, then inducing upward capillary flow from saturated bottom end to a specified time then changing moisture content of the soil was measured as a function of time $t$ and vertical distance z. The moisture content profiles were used to calculate the van Genuchten parameters $\mathrm{K}_{\mathrm{sat}}, \alpha$ and $\mathrm{n}$ by the inverse method using finite difference form of Richards' equation. And we use the resulting SWCC from the simplified model to evaluate the Gardner parameters, $\mathrm{K}_{\mathrm{sat}}$ and $\alpha$, of the $\mathrm{K}(\alpha)$ function for the Gardner (1958) equation as:

$\mathrm{K}(\psi)=\mathrm{K}_{\mathrm{sat}} \mathrm{e}^{\alpha \psi}$

As Eq. 1 is a nonlinear partial differential equation, therefore in solving this equation finite difference form has to be used. A soil column is divided into many segments of equal length $\Delta \mathrm{z}$. Considering the three segments of adjacent segments e.g. i-1, i and i+1 in Fig. 1 , water flow from $i-1$ to $i$ and to $i+1$. At any time $j, \psi_{i, j}$ and $\theta_{i, j}$ are pressure head and moisture content at the center of segment $i$, respectively.

Time is also divided by intervals of $\Delta \mathrm{t}$ such that $\mathrm{t}=$ $\mathrm{j} \cdot \Delta \mathrm{t}$. Then the derivatives in Eq. 1 are written as discrete differences divided by the appropriate interval:

$$
\begin{aligned}
& \frac{\theta_{i, j+1}-\theta_{i, j}}{\Delta t}=\frac{1}{\Delta z}\left[\begin{array}{l}
\frac{K_{i+1, j}+K_{i, j}}{2} \frac{\psi_{i+1, j}-\psi_{i, j}}{\Delta z} \\
-\frac{K_{i, j}+K_{i-1, j}}{2} \frac{\psi_{i, j}-\psi_{i-1, j}}{\Delta z}
\end{array}\right] \\
& +\frac{1}{\Delta z}\left[\frac{K_{i+1, j}+K_{i, j}}{2}-\frac{K_{i, j}+K_{i-1, j}}{2}\right]
\end{aligned}
$$


Am. J. Applied Sci., 635-643, 2011

Table 1: Textures and particle densities of the experimental soils Soil particles (\%)

\begin{tabular}{|c|c|c|c|c|c|}
\hline Site & Texture & Sand & Silt & Clay & $\begin{array}{l}\text { Particle } \\
\text { density }\left(\mathrm{kg} \mathrm{m}^{-3}\right)\end{array}$ \\
\hline$\overline{\mathrm{St} 1}$ & Sandy loam & 78.4 & 12.9 & 8.7 & 2,501 \\
\hline St2 & Sandy loam & 64.8 & 26.7 & 8.5 & 2,360 \\
\hline St3 & Sandy clay loam & 59.8 & 18.6 & 21.6 & 2,782 \\
\hline
\end{tabular}

Table 2: Physical properties of the soils

\begin{tabular}{lllllll}
\hline \multicolumn{7}{c}{ Bulk density } \\
Site & Texture & \multicolumn{1}{c}{ Compaction } & $\left(\mathrm{kg} \mathrm{m}^{-3}\right)$ & Porosity & $\theta_{\mathrm{r}}$ & $\theta_{\mathrm{s}}$ \\
\hline St1 & Sandy & Loose & 1,478 & 0.409 & 0.036 & 0.390 \\
& Loam & Dense & 1,618 & 0.353 & 0.037 & 0.346 \\
St2 & Sandy & Loose & 1,464 & 0.380 & 0.024 & 0.368 \\
& loam & Dense & 1,606 & 0.320 & 0.024 & 0.317 \\
St3 & Sandy & Loose & 1,479 & 0.468 & 0.062 & 0.439 \\
& clay loam & Dense & 1,621 & 0.417 & 0.062 & 0.416 \\
\hline
\end{tabular}

Therefore, the volumetric moisture content $\theta_{\mathrm{i}, j+1}$ in segment $i$ at the next time step is calculated from:

$$
\begin{aligned}
& \theta_{i, j+1}=\theta_{i, j}+\frac{\Delta t}{\Delta z}\left[\begin{array}{l}
\frac{K_{i+1, j}+K_{i, j}}{2} \frac{\psi_{i+1, j}-\psi_{i, j}}{\Delta z} \\
-\frac{K_{i, j}+K_{i-1, j}}{2} \frac{\psi_{i, j}-\psi_{i-1, j}}{\Delta z}
\end{array}\right] \\
& +\frac{\Delta t}{\Delta z}\left[\frac{K_{i+1, j}+K_{i, j}}{2}-\frac{K_{i, j}+K_{i-1, j}}{2}\right]
\end{aligned}
$$

where $\theta_{i, j}, \theta_{i, j+1}=$ volumetric moisture contents in segment $\mathrm{i}$ at time $\mathrm{j}$ and $\mathrm{j}+\Delta \mathrm{t}$, respectively; $\mathrm{K}_{\mathrm{i}-1, \mathrm{j}}, \mathrm{K}_{\mathrm{i}, \mathrm{j}}$, $\mathrm{K}_{\mathrm{i}+1, \mathrm{j}}=$ unsaturated hydraulic conductivities in segment $\mathrm{i}-1, \mathrm{i}$ and $\mathrm{i}+1$ at time $\mathrm{j}$, respectively; $\psi_{\mathrm{i}-1, \mathrm{j}}, \psi_{\mathrm{i}, \mathrm{j}}, \psi_{\mathrm{i}+1, \mathrm{j}}=$ pressure heads in segment $\mathrm{i}-1, \mathrm{i}$ and $\mathrm{i}+1$ at time $\mathrm{j}$, respectively.

\section{MATERIALS AND METHOD}

Experiment: To evaluate the soil water characteristic curve and measure the moisture content in soil column, a set of experiments was performed at the Soil and Water Laboratory, Khon Kaen University, Thailand. Prior to the experiment, a decision had to be made between the tensiometer measurement and the gravimetric method for measuring the soil moisture content. Because of the delay time in the tensiometer measurement, the gravimetric method was chosen. The experiments involved four steps: Soil sample and saline water preparation; inducing capillary rise; soil moisture content measurement; and calculation of hydraulic conductivity parameters.

Physical properties: Three saline soils collected from different locations around the city of Khon Kaen were used in the experiments. They were taken from the field down to about $1 \mathrm{~m}$ depth and brought back to the laboratory. Texture and particle density of the soil types are shown in Table 1. The textures of sample soils were classified by using the system of the U.S. Department of Agriculture (USDA). Two soil types are sandy loam texture and the other one is sandy clay loam. The size distributions of sample soils were analyzed by sieve method and sedimentary method and shown in Fig. 2.

Physical properties of the each soil are shown in Table 2. $\theta_{\mathrm{r}}$ and $\theta_{\mathrm{s}}$ are the residual and saturated volumetric moisture contents, respectively, which the volumetric moisture content $\theta$ is defined as the volume of water per bulk volume of soil, but it may be obtained from the gravimetric moisture content $\left(\theta_{\mathrm{m}}\right)$ by use of the formula:

$\theta=\frac{\rho_{\mathrm{b}}}{\rho_{\mathrm{w}}} \theta_{\mathrm{m}}$

where:

$\rho_{\mathrm{b}}$ and $\rho_{\mathrm{w}}=$ Bulk density of soil and density of water, respectively

Gravimetric moisture content $\left(\theta_{\mathrm{m}}\right)$ was measured directly and then is obtained by dividing the mass of soil water by the mass of the dry soil. The residual gravimetric moisture content is obtained from soil sample that was dried at room temperature in the laboratory, while the saturated gravimetric moisture content was measured by filling the sample soil into the core and compact it. The core is then immersed the tip of the lower end into a pool of water for about 48-hrs, then bring it up to weigh and oven dry and weigh the dry sample again. After it has come to constant weight in an oven at a temperature between $100^{\circ} \mathrm{C}$ and $110^{\circ} \mathrm{C}$, reweighing the soil core to determine the amount of water removed.

Setting up the soil columns: The soil samples were dried at room temperature in the Soil and Water Laboratory, Khon Kaen University and disaggregated with a rubber hammer. Each sample was filled in a tube made up with a connection series of a 5-cm height of stainless steel tube $4.8-\mathrm{cm}$ inside diameter. The filling soil column was compacted at every $1.5-\mathrm{cm}$ height with a PVC rod has end plug 4.2-cm diameter, $60-\mathrm{cm}$ in length and 350 grams in weight. Two standardized compactions were performed for each test, one was 2 strokes (loose) the other was using 10 strokes (dense) and the height of stroke was $15 \mathrm{~cm}$. 
Am. J. Applied Sci., 635-643, 2011

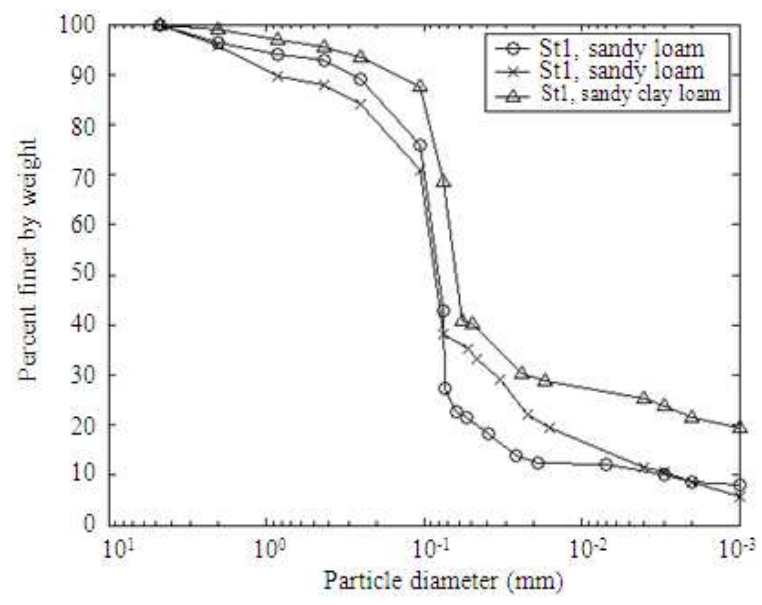

Fig. 2: Soil distributions of the experimental soils

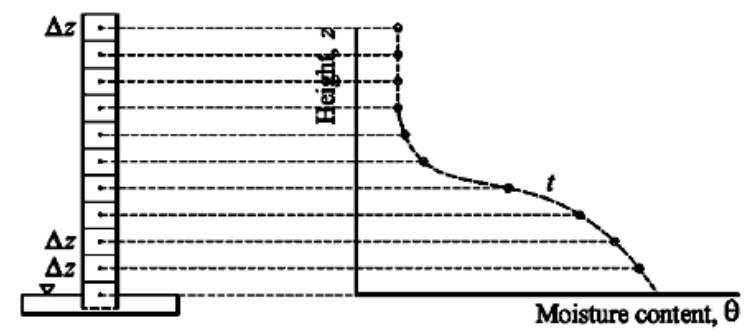

Fig. 3: Soil column setting and its moisture content profile

Capillary flow test: Eight columns, 4 each for loose compacted and dense compacted, were prepared for the type 1 sandy loam (St1). And the other eight columns were prepared for the type 2 sandy loam (St2). Eight columns, 4 for loose compacted and the other 4 for dense compacted, were prepared for the sandy clay loam (St3). Each soil column was placed by immersing the lower end into a pool of saline water about 150 $\mathrm{mS} / \mathrm{cm}$ at the depth of $2.5-\mathrm{cm}$ below the water surface as shown in Fig. 3.

For the two sandy loam samples (St1 and St2), the lengths of time allowed capillary flow taking place were 3, 6, 12 and $24 \mathrm{hrs,}$, while for the sandy clay loam sample (St3) the lengths of time were 1, 2, 3 and 4 days. After a specified time, each soil column was separated into individual stainless steel tube. The moisture content of each tube was measured.

Wetting soil water characteristic curves: The SWCC relation of pressure head $(\theta)$ to moisture content $(\theta)$ which is a fundamental soil property. The relationship is obtained by: (1) taking an initially saturated sample and applying suction or pressure to dry it (drying primary SWCC), or by (2) gradually wetting an initially dry soil (wetting primary SWCC). For calculation of the capillary flow in soil, it is necessary to use the wetting primary SWCC. A wetting SWCC can be obtained by using a hanging column apparatus to induce moist soil of known pressure head or by calculation from the capillary flow in dry soil column. In this study we calculate it by using inverse method and compare it to data from hanging column test.

Method of calculation: Since our work is to search for a simplified method to evaluate unsaturated hydraulic conductivity function for saline soil that is cooperate with the van Genuchten's formula therefore we explain our resulting procedure here. The method comprises setting up a soil column with a specified bulk density compacted soil then allowing capillary flow with saline water to be taken place from the bottom end in the uniform initial moisture content for a specified period of time.

In this study, we use the inverse method to determination of the $K(\theta)$ and SWCC for van Genuchten (1980) equations by using the proposed numerical model and trial the parameters $\mathrm{K}_{\mathrm{sat}}, \alpha$ and $\mathrm{n}$. The best fit between the measured and this model calculation is found by an optimization procedure which adjusts the parameters of $\mathrm{K}(\theta)$ and SWCC.

Also we fit the Gardner's formula to the data sets by trial the Gardner parameters $\left(\mathrm{K}_{\text {sat }}\right.$ and $\left.\alpha\right)$ with using the resulting SWCC from the van Genuchten parameters $\alpha$ and $n$. In addition, we use the resulting values of van Genuchten parameters $\left(\mathrm{K}_{\mathrm{sat}}, \alpha\right.$ and $\left.\mathrm{n}\right)$ to evaluate the capillary flow with the HYDRUS-1D and compare to this proposed model calculation.

\section{RESULTS}

The fitting curves of capillary flow with the data points for the sandy loam soils of stations St1 and St2 are shown in Figs. 4-5 respectively and for the sandy clay loam of station St3 is in Fig. 6. By proposed model using van Genuchten (1980) equation are shown as solid lines, Gardner (1958) equation as dashed lines and the data points as symbols.

The resulting parameters of the van Genuchten equation and Gardner equation of each soil type are shown in Table 3. 
Am. J. Applied Sci., 635-643, 2011

Table 3: The resulting parameters of the proposed models of each soil type

\begin{tabular}{|c|c|c|c|c|c|c|c|c|}
\hline \multirow[b]{2}{*}{ Station/texture } & \multirow[b]{2}{*}{ Compaction } & \multicolumn{4}{|c|}{ van Genuchten's parameters } & \multicolumn{3}{|c|}{ Gardner's parameters } \\
\hline & & $\mathrm{a}\left(\mathrm{cm}^{-1}\right)$ & $\mathrm{n}$ & $\mathrm{K}_{\text {sat }}\left(\mathrm{cm} \mathrm{d}^{-1}\right)$ & $\mathrm{R}_{\text {avg }}^{2}$ & $\mathrm{a}\left(\mathrm{cm}^{-1}\right)$ & $\mathrm{K}_{\text {sat }}\left(\mathrm{cm} \mathrm{d}^{-1}\right)$ & $\mathrm{R}_{\text {avg }}^{2}$ \\
\hline$\overline{\text { St1 }}$ & Loose & 0.015 & 2.18 & 12.0 & 0.947 & 0.039 & 14.0 & 0.946 \\
\hline (Sandy loam) & Dense & 0.008 & 2.15 & 3.0 & 0.942 & 0.018 & 3.0 & 0.936 \\
\hline St2 & Loose & 0.020 & 2.70 & 44.0 & 0.974 & 0.058 & 75.0 & 0.969 \\
\hline (Sandy loam) & Dense & 0.017 & 2.77 & 39.0 & 0.969 & 0.064 & 108.0 & 0.980 \\
\hline St3 & Loose & 0.015 & 3.40 & 1.7 & 0.923 & 0.051 & 4.4 & 0.929 \\
\hline (Sandy clay loam) & Dense & 0.014 & 2.84 & 0.4 & 0.995 & 0.037 & 0.6 & 0.994 \\
\hline
\end{tabular}

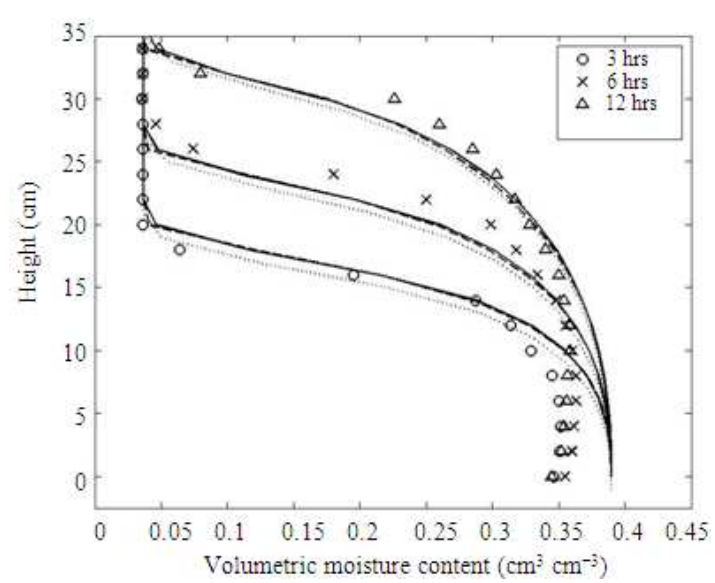

(a)

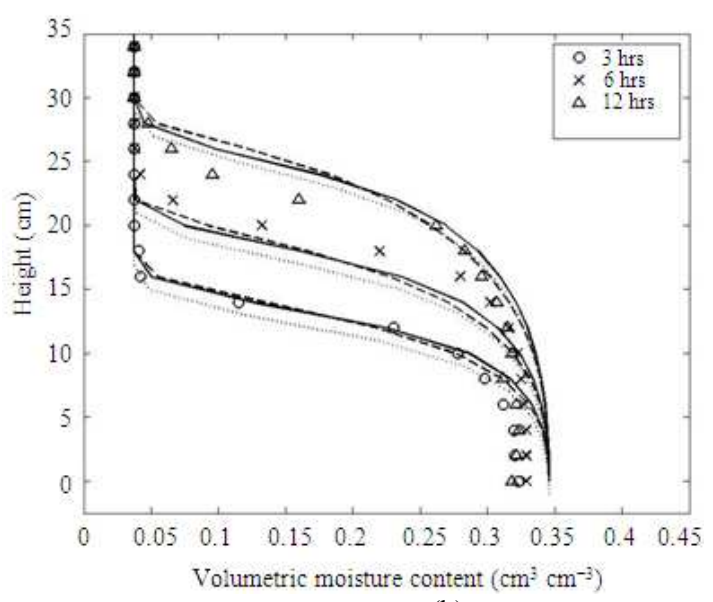

(b)

Fig. 4: Measured and fitted capillary flow for compacted soil station St1 by proposed models

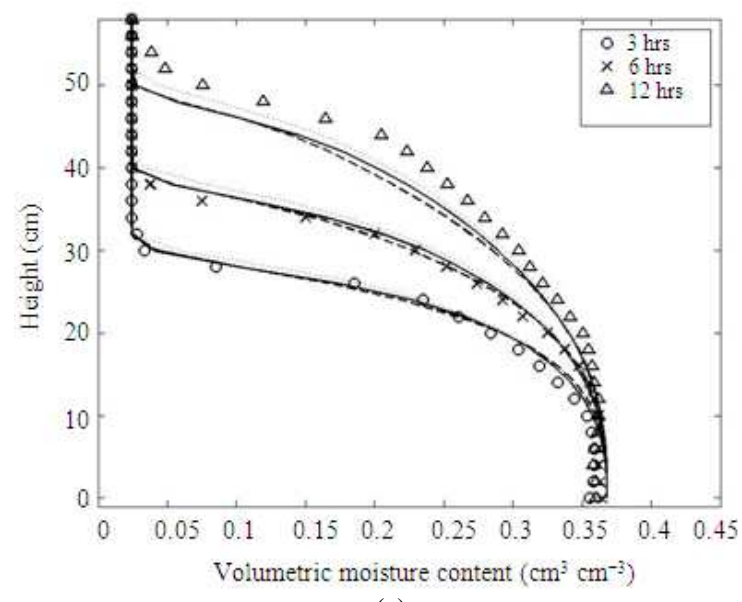

(a)

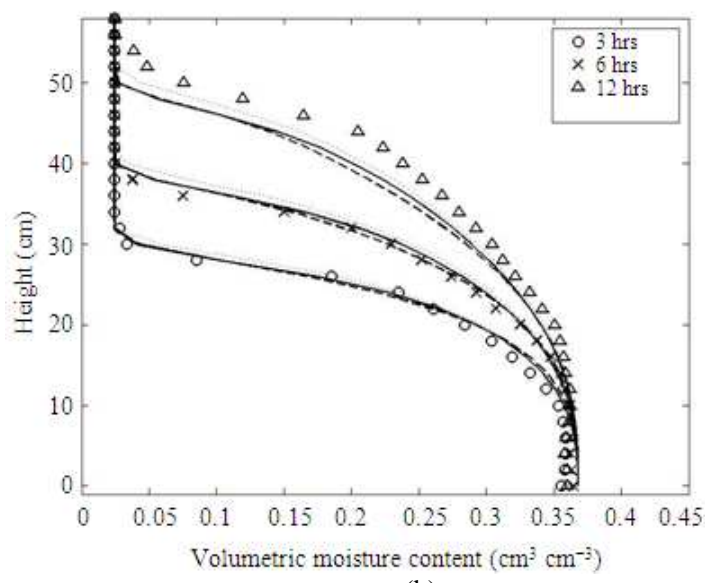

(b)

Fig. 5: Measured and fitted capillary flow for compacted soil station St2 by proposed models

The resulting wetting SWCC of the proposed model using the van Genuchten (1980) equations for loose and dense soil station St1-St3 are shown in Figs. 7a-c, respectively and compare to data from hanging column test.

The resulting values of $K(\theta)$ of the proposed model using the van Genuchten (1980) and Gardner (1958) equations for loose and dense soil station St1, St2 and St3 are shown in Figs. 8a-c, respectively. Using the resulting parameters to predict the capillary flow for each soil type by proposed models are shown in Figs. 9-11. 
Am. J. Applied Sci., 635-643, 2011

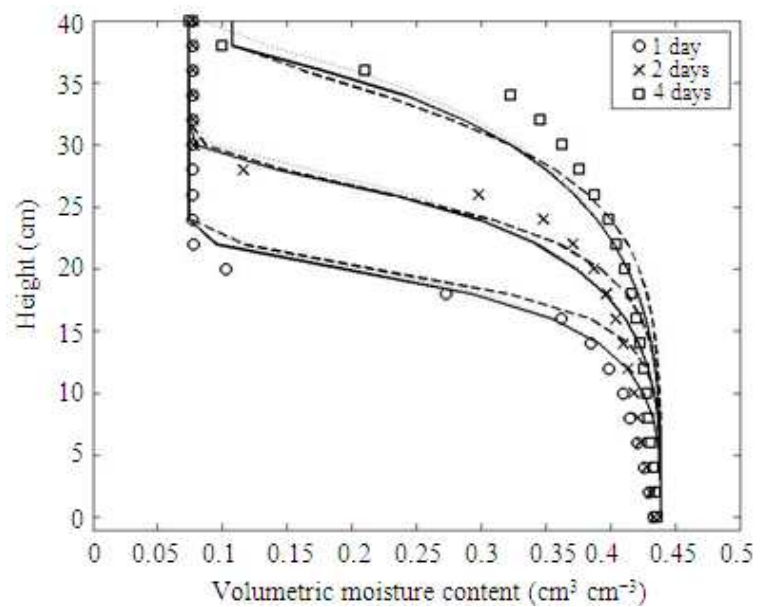

(a)

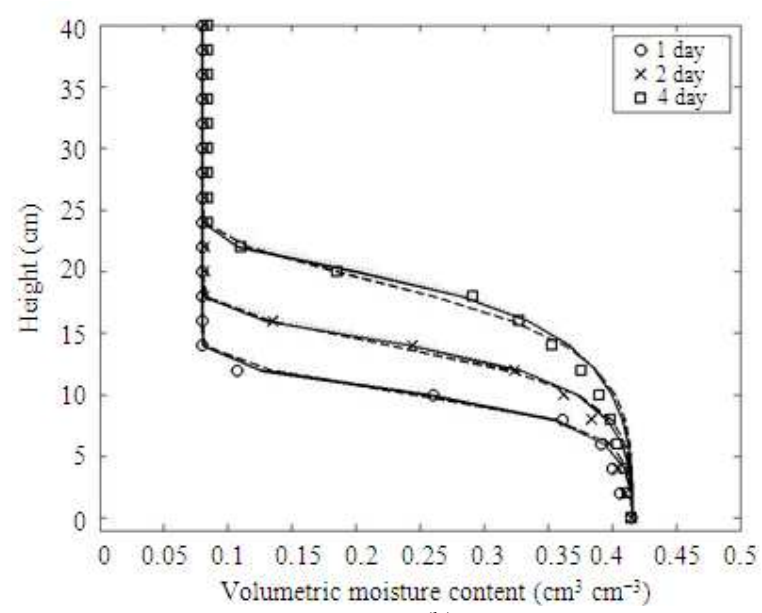

(b)

Fig. 6: Measured and fitted capillary flow for compacted soil station St3 by proposed models

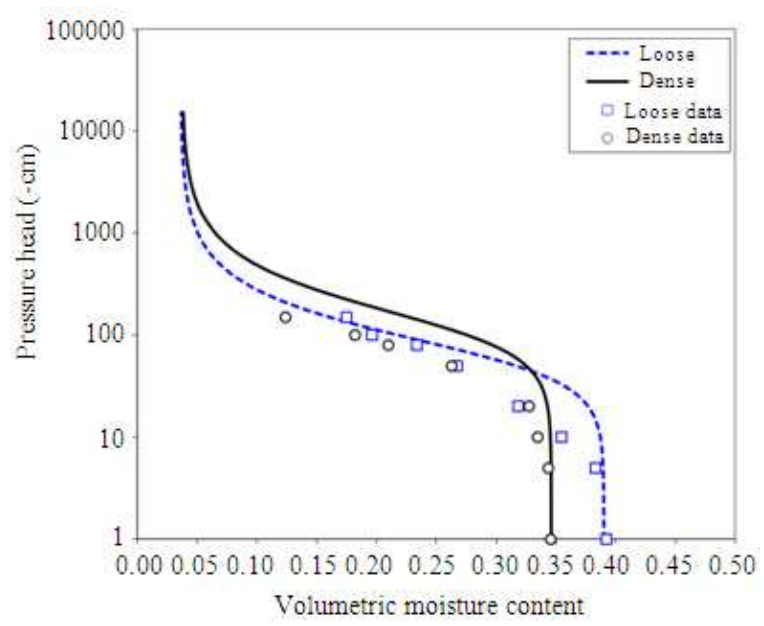

(a)

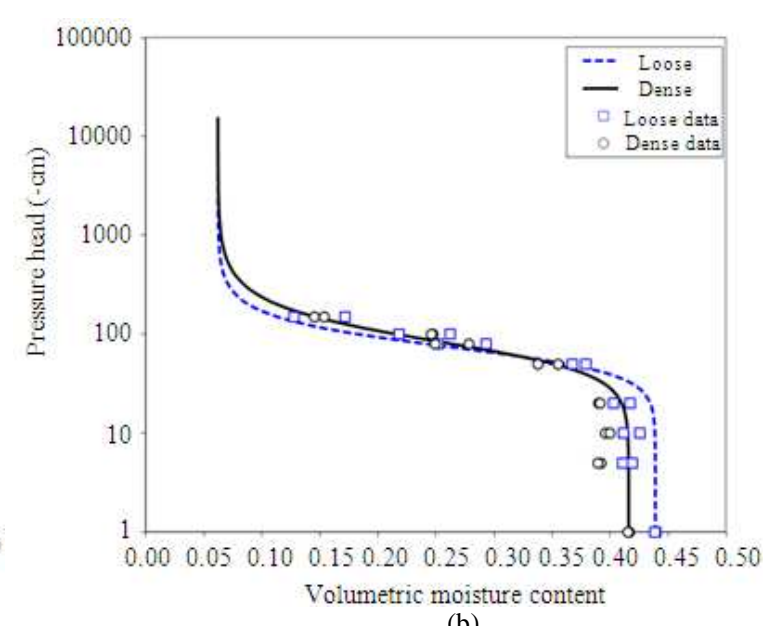

(b)

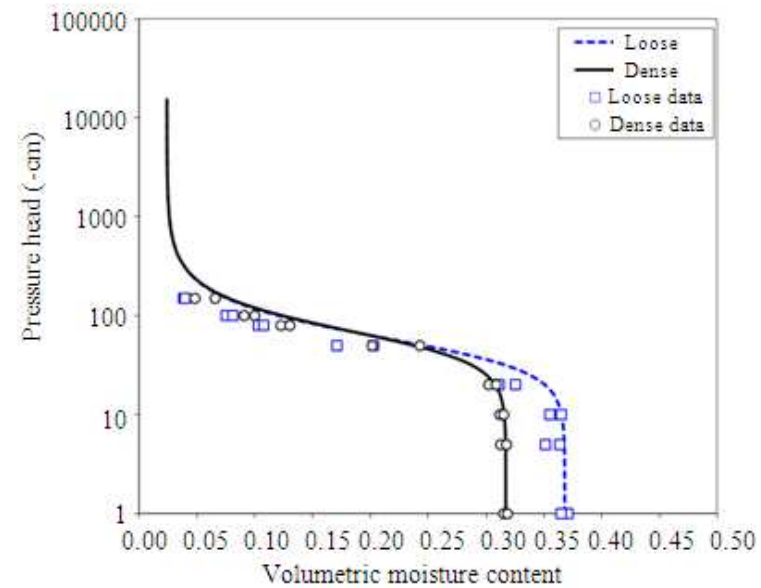

(c)

Fig. 7: The resulting wetting SWCC of the van Genuchten (1980) equations for loose and dense soil 
Am. J. Applied Sci., 635-643, 2011
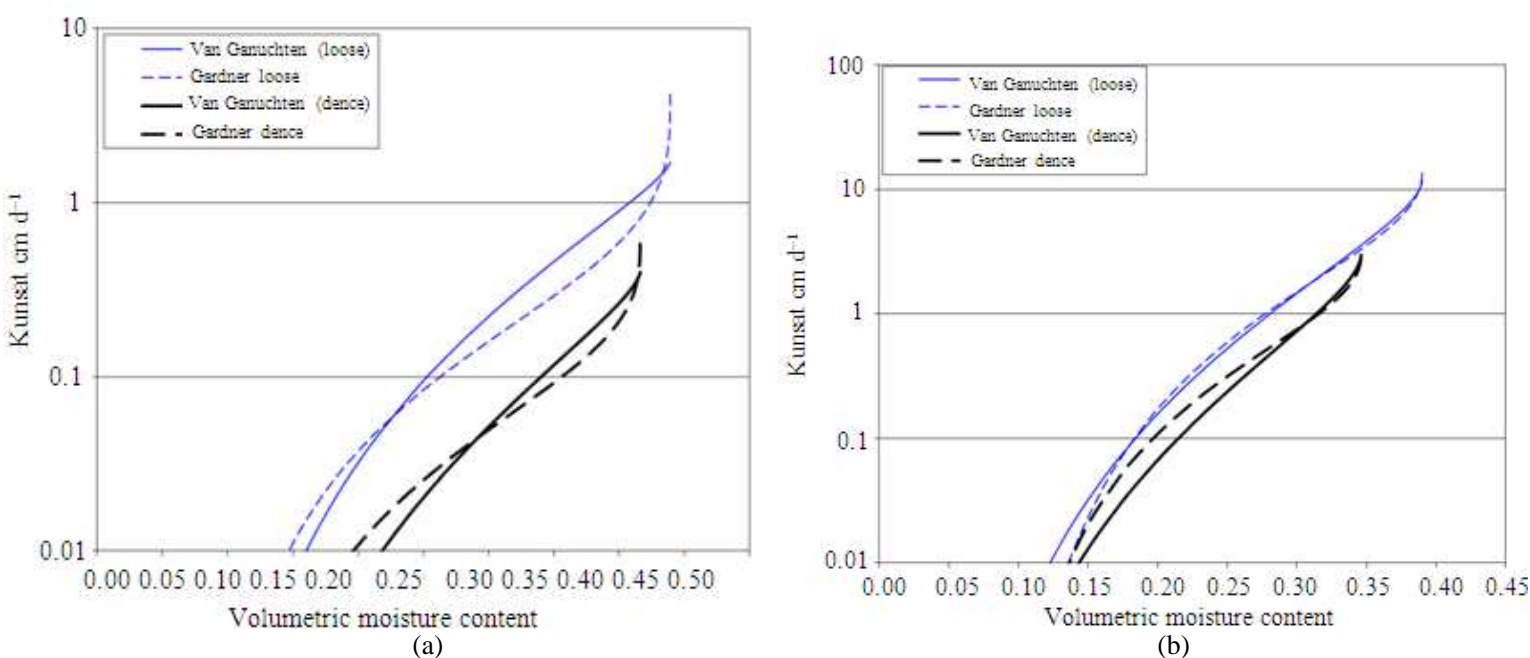

(b)

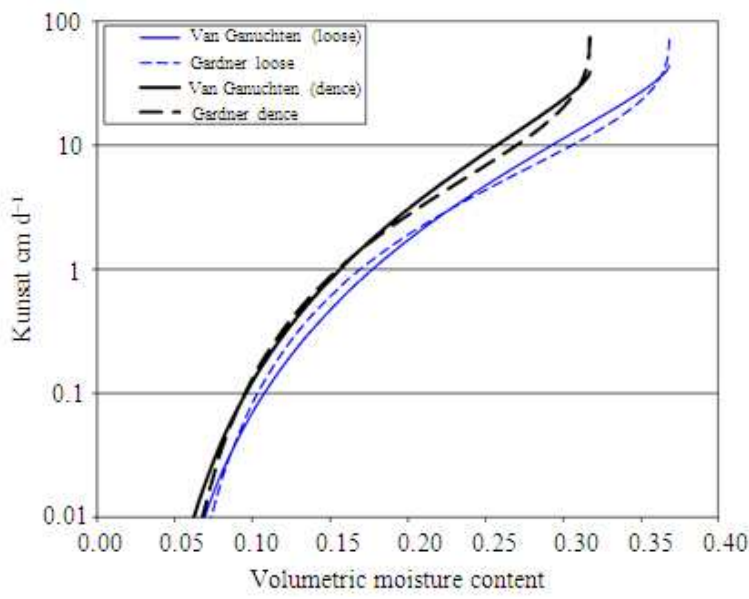

(c)

Fig. 8: The resulting $K(\theta)$ of the van Genuchten (1980) and Gardner (1958) equations for loose and dense soil

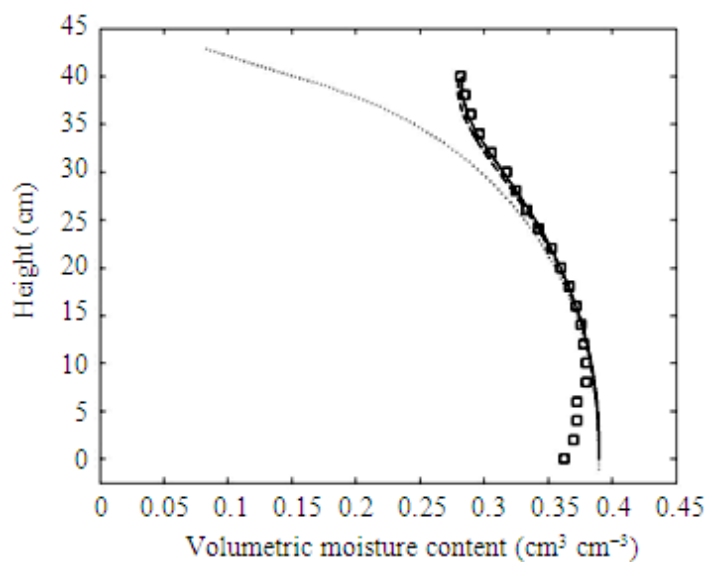

(a)

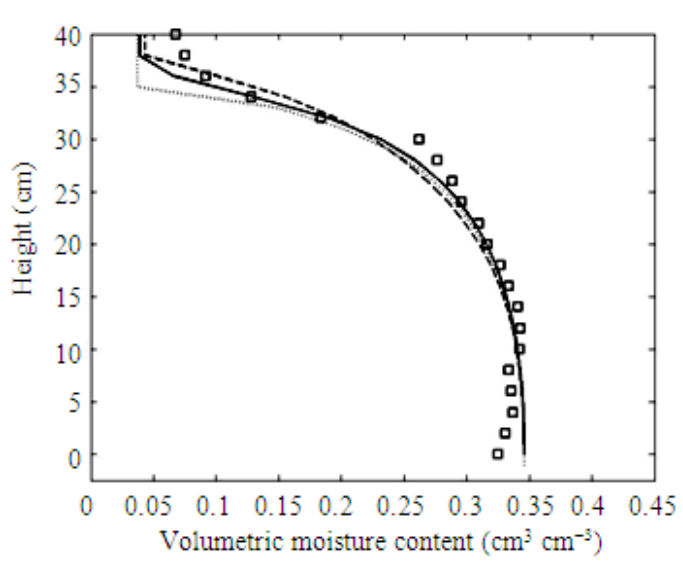

(b)

Fig. 9: Measured and predicted capillary flow for compacted soil station St1 by proposed models (a) Loose compact $\rho_{\mathrm{b}}=1,478 \mathrm{~kg} \mathrm{~m}^{-3}$ (b) Dense compact $\rho_{\mathrm{b}}=1,618 \mathrm{~kg} \mathrm{~m}^{-3}$ 


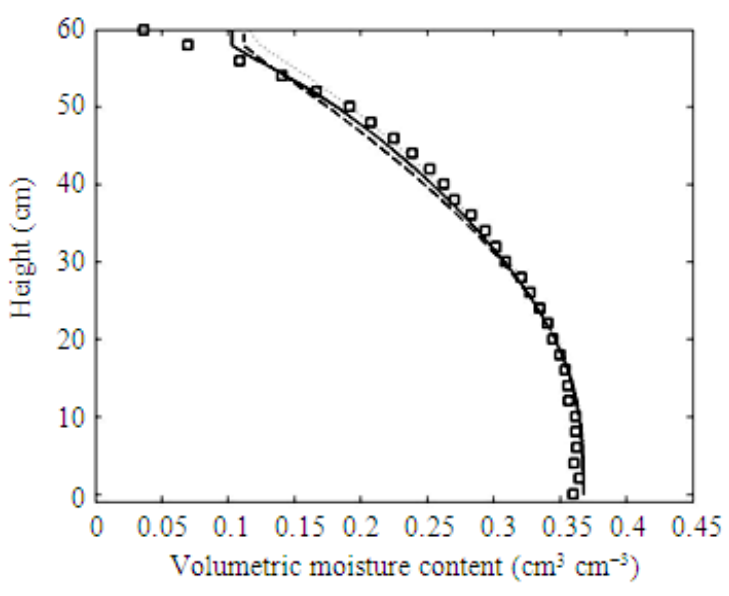

(a)

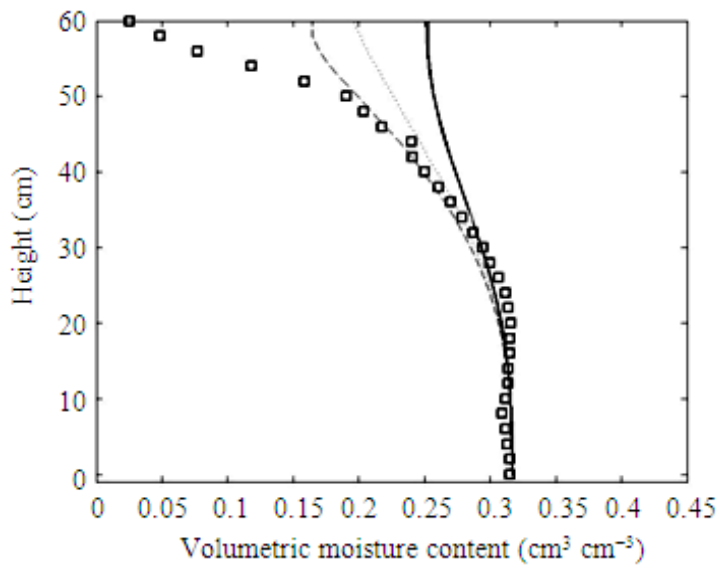

(b)

Fig. 10: Measured and predicted capillary flow for compacted soil station St2 by proposed models (a) Loose compact $\rho_{\mathrm{b}}=1,464 \mathrm{~kg} \mathrm{~m}^{-3}(\mathrm{~b})$ Dense compact $\rho_{\mathrm{b}}=1,608 \mathrm{~kg} \mathrm{~m}^{-3}$

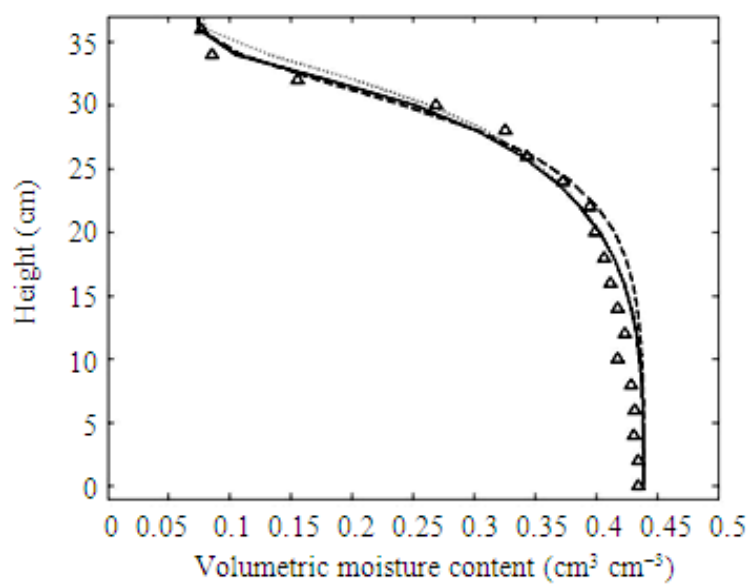

(a)

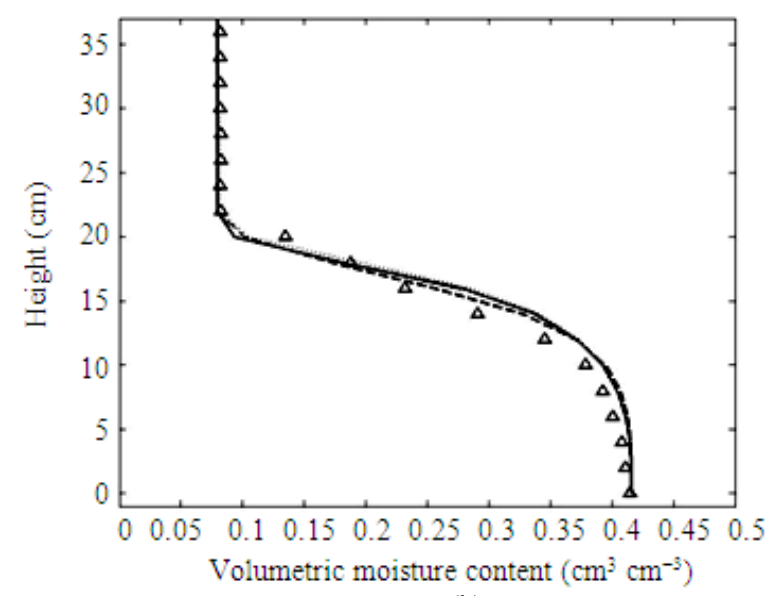

(b)

Fig. 11: Measured and predicted capillary flow for compacted soil station St3 by proposed models (a) Loose compact $\rho_{\mathrm{b}}=1,479 \mathrm{~kg} \mathrm{~m}^{-3}$ (b) Dense compact $\rho_{\mathrm{b}}=1,621 \mathrm{~kg} \mathrm{~m}^{-3}$

\section{DISCUSSION}

The discrepancies of the $\theta_{\mathrm{s}}$ between measurement and fitting formulas for St1 and St2 (Fig. 4-5) may be from erroneous measurement. Since the $\theta_{\mathrm{s}}$ values should not be less than the unsaturated moisture content $\theta_{\text {unsat }}$ values. The bottom ends of the soil columns for sandy loam type may lose some water during lifting the columns off the pool of saline water. This may be one reason for the discrepancies for sandy loam but not for sandy clay loam.

The $\mathrm{K}_{\text {sat }}$ values for sandy clay loam, however, are much less than those for sandy loam. Most values of $K_{\text {sat }}$ for the van Genuchten (1980) equations are lower than the Gardner (1958) equation, while it is equal for dense sandy loam St1. Nearly overall of $\mathrm{K}_{\text {sat }}$ values of dense soil are lower than loose soil, except for sandy loam St2 by Gardner equation.

These $\mathrm{K}_{\text {sat }}$ values were used in the HYDRUS-1D model to evaluate the soil water flow in the three soil types as the dotted lines in Fig. 4-6. The dotted lines from HYDRUS-1D show similar results with the calculated curves using this method.

\section{CONCLUSION}

- This simplified proposed method is able to determine the unsaturated hydraulic conductivity and wetting soil water characteristic curve for saline soil with accurate results 
- The capillary flow simulations were experimented using a one-dimensional soil column in laboratory test and evaluated using a finite difference form of Richards' equation

- The relationships of moisture content and vertical distance of capillary flow above the water table can be used to calculate $\mathrm{K}_{\mathrm{sat}}$ and soil water characteristic curve by inverse method

- All values of $\mathrm{K}_{\text {sat }}$ for the van Genuchten (1980) equations are lower than the Gardner (1958) equation except that for dense sandy loam St1 which show equal values

- The $\mathrm{K}_{\mathrm{sat}}$ values of dense compacted soil are almost entirely lower than loose compacted soil, except for sandy loam St2

- This method is simple and appropriated for measurement of hydraulic parameters by laboratory methods

\section{ACKNOWLEDGEMENT}

The researchers would like to thank the Groundwater Research Center (GWRC), Khon Kaen University and Faculty of Engineering, Mahasarakham University for funding this research. We would also like to thank the Departments of Civil Engineering and Agricultural Engineering, Khon Kaen University, for providing laboratory facilities.

\section{REFERENCES}

Arunin, S., 1992a. Strategies for utilizing salt affected lands in Thailand. Proceedings of the International Symposium on Strategies for Utilizing Salt Affected Lands. Bangkok, 17-25 February 1992. Bangkok, Department of Land Development, Ministry of Agriculture and Cooperatives, pp: 26-37. http://library.wur.nl/WebQuery/clc/912522.

Gardner, W.R., 1958. Some steady-state solutions of the unsaturated moisture flow equation with application to evaporation from a water table. Soil Sci., 85: 228-232. DOI: 10.1097/00010694195804000-00006.

Konyai, S., V. Sriboonlue and V. Trelo-ges, 2009. The Effect of Air Entry Values on Hysteresis of Water Retention Curve in Saline Soil . American Journal of Environmental Sciences, 5: 341-345. DOI: 10.3844/ajessp.2009.341.345.

Loffler, E. and J. Kubiniok, 1988. Soil salinization in north-east Thailand. Erdkunde, 42: 89-100. DOI: 10.3112/erdkunde.1988.02.01.

Richards, L.A., 1931. Capillary conduction of liquids in porous mediums, Physics. 1: 318-333. DOI: 10.1063/1.1745010.

van Genuchten, M.T., 1980. A closed-form equation for predicting the hydraulic conductivity of unsaturated soils. Soil Sci. Soc. Am. J., 44: 892-898. DOI: 10.2136/sssaj1980.03615995004400050002x. 